\title{
Is English Our Lingua Franca or the Native Speaker's Property? The Native Speaker Orientation among Middle School Students in Japan
}

\author{
Akihiro Saito \\ Center for Liberal Arts and Sciences, Hachinohe Institute of Technology, Japan \\ Email: akihiro.saito@usq.edu.au
}

\begin{abstract}
This paper reports the first empirical study to date that sought to examine the native speaker orientation among middle school EFL students in Japan. To this end, this preliminary study measured their language attitudes in this respect addressing age-stratified and gender variations. The data was elicited from an attitude survey with 318 eighth and ninth graders at a public middle school. The findings suggest that the students gave significantly more positive evaluations to native than to nonnative varieties of English. Second, they opted for learning English for its currency and utility in the English as a native language setting, rather than for its transnational function as a lingua franca. Lastly, the finding indicated a possible developmental trajectory of their native speaker orientation.
\end{abstract}

Index Terms - language learning, language attitudes, native speaker, Japan, English as a lingua franca

\section{INTRODUCTION}

While the transnational function of English as a lingua franca is well documented in the literature (e.g., Brutt-Griffler, 2002; Crystal, 1997; Graddol, 2006; Jenkins, 2007; Kachru, Kachru, \& Nelson, 2006; Pennycook, 2007), the notion of English as the language of the native speaker in its parochial sense is purported to persist in Japanese society (i.e., as the language of the British and North Americans in particular) (see Matsuda, 2002). As such, native speakership constitutes the nexus of marketing and publicity strategies in the popular private eikaiwa gakkô (i.e., English conversation teaching schools) industry (see Joe, 2010; Seargeant, 2005). Their commercial ads abound with rhetoric such as, native speaker no eigo ('native speakers' English'), hom'mono no eigo ('authentic English'), and native speaker no kôshi ('native-speaker instructors'). Native speakership thereby indexes the claim of the aesthetic that both the existing and potential clientele should aspire to. This reproduces the myth of the authenticity of the native speaker (Seargeant, 2005), which is out-dated in view of the purported language globalization underway (see Dörnyei, Csizér, and Németh, 2006).

Indeed, the concept of native speaker has been a contested one in its own right (Kravchenko, 2010; see also Doerr, 2009). The elusive complexity of native speaker status, both in terms of judgments of language and identity, is noted in the literature (e.g., Davies, 2003). In terms of judgments of language, there is empirical evidence, for instance, that native and nonnative speaker of a language fail to recognize each other if the nonnative speaker is very proficient in that language (Davies, 2003, pp. 199-200). People cannot necessarily tell the native speaker with a high level of accuracy by the mere characteristics of the language that he or she speaks. Native speaker status begs the question of identity also. Davies (2003) makes the following comment on the identity of the native speaker:

To be a native speaker means not being a non-native speaker. Even if I cannot define a native speaker I can define a non-native speaker negatively as someone who is not regarded by him/herself or by native speakers as a native speaker. (p. 213)

In a similar vein, Kravchenko (2010) argues "a native speaker's 'performance' is something by which he may be identified by other native speakers as 'one of us', in contrast to 'them' as 'not us"' (p. 680).

Matsuda (2003) reported a qualitative case study of the beliefs about the ownership of English among Japanese high school students. She demonstrated that the participants held a view that English is the property of the native speaker of the language and that they merely stand on the margin of the global English arena. In fact, students' idea about Anglophones was mostly limited to those from the UK and US (p. 488). In other words, for these Japanese students, English speakers meant those who (are purported to) possess native speaker status. Thus, in contrast to the current scholarly theorizing of global English, the Japanese students in her study did not identify themselves as members of the global community.

From the pedagogical point of view, a negative implication of holding the native speaker orientation is noted in the literature. Japanese learners strive to "perfect" their English to be like that of the native speaker, nurturing negative perceptions about nonnative varieties and speakers of English (Honna, 1995; Honna \& Takeshita, 2000). As Honna 
(1995) points out:

Japanese students of English not only cannot accept their limited proficiency as natural and inevitable, but also look down on nonnative varieties of English used by Asian and African speakers [and] hesitate to interact with English speakers 'until', as they are often heard to say, 'they develop complete proficiency in the language'. (p. 58)

The purported native speaker ideal holds parallels with pedagogical practices as observed in Japan. While the contemporary English language teaching (ELT) scene has witnessed deliberate attempts to incorporate world Englishes (see e.g., Sakai, 2005), the role model in English as a foreign language (EFL) contexts generally remains an exonormative native speaker one (Kirkpatrick, 2007). By the same token, North American and British English have been the preferred varieties in Japan (Loveday, 1996; Morrow, 2004). This preference remains current in the Japanese ELT industry. In this respect, Matsuda (2002) explored the representation of English users and uses in Japanese government-authorized textbooks of English. She discovered that these textbooks tended to emphasize native uses and users of English, such as North American, British, and Australian. Goddard (2001) investigated how teachers in Japan approach ELT with what level of awareness of the regional variation of English. His survey demonstrated that even among skilled and knowledgeable teachers, there was a paucity of attention to regional variation of the language, and hence, an absence of a systematic approach to address the learner's awareness of varieties of English (Goddard, 2001, p. 22). These findings point to the potential gap between the current scholarly reconfiguration of the role model of English (Kirkpatrick, 2007; Seidlhofer, 2001), and the folk perceptions and ELT practices as observed in Japan.

The literature suggests that the exonormative model of English not only devalues local nonnative teachers and undermines their self-confidence, but also projects the goal of learning the language as to be unattainable in the eyes of the great majority of students (Kirkpatrick, 2007). In face of this deficiency of the exonormative model, a pedagogical reformation has been proposed with a view to effective international and cross-cultural communication, as opposed to the acquisition of the native speaker's norm (e.g., Jenkins, 2009; Kirkpatrick, 2007; Mauranen, 2006; Seidlhofer, 2003). In this connection, to what extent language learners perceive the ownership of global English to rest with themselves as nonnative speakers merits empirical verification. This applies, in particular, to the periphery such as Japan where people purportedly perceive the English language not as their own property (Matsuda, 2003). If in one small corner of the globe, people do not have a sense of ownership of English as a lingua franca due to a belief in the myth of the native speaker, then this will hold important ramifications for theory and practice.

Upon this justification, the present study sought to measure language learner attitudes in this respect drawing upon the framework of language attitudes (e.g., Baker 1992; Gardner, 1985; Garrett, 2010; Garrett, Coupland, \& Williams, 2003; Ryan \& Giles, 1982). There are several language attitude studies in Japan that reported a preference for native varieties of English among tertiary students (Chiba, Matsuura, \& Yamamoto, 1995; Matsuura, Chiba, \& Yamamoto, 1994) and high school students (Fraser, 2006; Matsuda, 2003; Saito \& Hatoss, 2011). Studies that specifically addressed the native speaker ideal within the context of language attitude are those by Matsuda (2003) and Saito and Hatoss (2011). To reiterate, Matsuda (2003) demonstrated a strong belief among high school students that English was the property of its native speakers. In their survey-based psychometric study, Saito and Hatoss (2011) reported that the native speakership orientation persists strongly among high school students in Japan.

Meanwhile, there has been no study to date in respect of the native speaker ideal among middle school students. Researching this particular population is critical, as the vast majority of Japanese students embark on EFL at middle school ${ }^{1}$, and therefore the findings of such a study will have great significance for EFL pedagogy. In particular, there is a paucity of research on Japanese language attitudes that addresses the different segments of a population in question such as age and gender (Starks \& Paltridge, 1996). Since attitudinal differences within a population could be a reflection of attitude change or demographic difference thereof, they might serve useful purposes-policy and planning, curricular, or pedagogical - when targeted separately. Therefore, in order to enhance its explanatory and application potentiality, the study addressed the possible age-stratified and gender-specific variations in attitudes also.

\section{ReSEARCH QueSTIONS}

The aim of the present study was three-fold. First, it sought to examine whether Japanese middle school students show a native speaker orientation in their attitudes towards different varieties of English. The second aim was to see whether they show any different disposition towards learning English according to the prospect of interacting with native speakers of English in the future. Third, it sought to ascertain whether there were any age-stratified and gender differences in their dispositions that indicate a native speaker orientation. Thus, the following three research questions were elaborated:

1. Do Japanese middle school students' attitudes differ towards native and nonnative varieties of English?

2. Do they display any difference in motivational disposition according to whether they associate learning the language with a setting where English is the primary language?

3. Do their language attitudes show any age-stratified and gender-specific variations?

\section{THEORETICAL UNDERPINNINGS}

\section{A. Language Attitudes}


According to Baker, a survey of perceptions of a language and language learning — language attitudes-provides insights into the current community thoughts and beliefs, and preferences and desires pertaining to second and foreign language learning (Baker, 1992, p. 9). Since any given language learning context embraces its own local sociocultural particularities, an investigation of folk perceptions of sociolinguistic variations and the significance for them of learning the target language (see Niedzielski \& Preston, 2000) provides essential pedagogical information. The point here lies not in the objective truth but rather in the learners' subjective reality, because it is their perceptions that will influence their choices and behaviors in language learning (Riley, 1997, p. 127). Thus, language attitudes in this study were seen as an amalgam of learners' attitudinal disposition towards different varieties of English and learning English.

The major implication of attitudes for language learning and teaching is the predictive power of these attitudes with respect to any number of dependent behaviors. Attitudes can predict behavior insofar as they are strongly activated and/or when one clearly perceives a link between one's attitude and behavior (Ajzen, 1996; see also Greenwald \& Banaji 1995, p. 7). Although there is considerable evidence that attitudes do not always predict behavior, this lack of accord itself is of interest in terms of language learning and use which involves a long-term commitment compared to, for example, buying a car (Garrett et al., 2003, p. 9). People may, for instance, strategically conceal their accent to which they are otherwise strongly loyal, knowing this enhances their chances of getting a job, thus helping them achieve their career goals.

\section{B. Attitude to Language}

While no language or language variety is superior or inferior in its own right (e.g., Edwards, 1979), each is subject to attitudes which represent “a person's evaluation of [a] psychological object” (Ajzen \& Fishbein 1980, p. 26). Psychologically, one's attitude emerges as one responds to an object evaluatively. This attitude formation process operates in the context of one's personal experiences, social interactions, and indirect information about the object (Aronson, Wilson, \& Akert 2005, p. 201). Indeed, past scholarship suggests that attitudes to language varieties are inherently informed by knowledge of the social connotations that these varieties possess for those people familiar with them (see Edwards, 1982). A great deal of attitude research has been conducted with recorded speech samples of languages or language varieties by eliciting evaluations given to them by research participants as judges; the judgments are then considered to represent stereotyped reactions to these varieties (see also Garrett, 2010, p. 32). The speech samples act as identifiers for the judge, allowing his or her expression of social stereotypes. Thus, in fact, despite the guise that it is the speech sample which the judge evaluates, it is not the speech per se which is evaluated, but rather the speaker (Edwards, 1982, p. 22). Indeed, since attitude research in general conceives of the speech sample as a cue evoking a stereotype of the speech community to which the speaker belongs, other identifiers such as written descriptions of the speech community might elicit quite the same social connotations. In sum, measured language attitudes inherently reflect some social connotations attached to the speakers of the language varieties in question.

\section{Attitude to Language Learning}

Attitude as a theoretical construct is closely associated with motivational dispositions in language learning (Baker, 1992). The classic distinction between integrative and instrumental attitudes emerged from the speculation that language learners' attitudes to the target language and culture, as well as to the goals to be achieved or the practical value and advantages conferred by a proficiency in the language, would have a significant impact on attitudes to second language learning and thus its outcomes (Gardner \& Lambert, 1972). Integrative attitude is "reflecting a willingness or a desire to be like representative members of the 'other' language community, and to become associated, at least vicariously, with that other community" (Gardner \& Lambert 1972, p. 14), while instrumental attitude is "characterised by a desire to gain social recognition or economic advantages through knowledge of a foreign language" (Gardner \& Lambert 1972, p. 14). These concepts are now refined and incorporated in the theories of second/foreign language learning (henceforth, L2) motivation research (see e.g., Dörnyei, 2005, Dörnyei \& Ushioda, 2009; 2011).

It is hence important to emphasize that L2 motivation as a theoretical construct is a complex and multidimensional one. Needless to say, researching this construct in its entirety demands a deliberate methodological planning. Meanwhile, this study focuses on native speaker orientation and its magnitude among (a group of) Japanese middle school students; it will not address L2 motivation in its broad conceptual and methodological spectrum. The main concern here is how native speaker orientation will be revealed in students' attitudes to English language learning. Specifically, the study sought to explore a possible variability in attitudes towards English language learning according to two simulated frames: the native speaker setting where English is the primary language and participants are likely to use English for interaction with native speakers, and the lingua franca setting in which participants are likely to use English for communication with nonnative speakers of English. As reported subsequently, the possible context-dependent difference in the dispositions in this respect was sought by repeating the same measurement items in these two frames.

\section{THE STUDY}

\section{A. Participants}

The survey took place at a public middle school located in the suburban area of a coastal city in central Japan. 
Permission for data collection at the school was granted by the principal, and 338 students consented to participate (Table 1). At this school, while the post graduation pathways of the students mostly converged on public and private high schools, the programs of these high schools that they sought to enroll in were varying, ranging from academic university-bound to technical ones (e.g., agricultural, industrial, and commercial). In the high school admission test in Japan, which is high-stakes (see Saito, 2006), English is normally given equal weight as the other subjects (i.e., mathematics, sciences, social studies, and Japanese language arts). Demographic information such as age, gender, linguistic background, and cross-linguistic contact, was sought as part of the survey. All of the students were Japanese. No multilingual background was reported. The duration of their English language learning as a school subject by the time the survey took place was one and a half years for the eighth graders, and two and a half years for the ninth graders. Twenty students who did not complete the grade and gender questions were eliminated from the subsequent analysis.

TABLE 1

DISTRIBUTION OF PARTICIPANTS ACCORDING TO GRADE AND GENDER

\begin{tabular}{lllll}
\hline & Grade 8 & Grade 9 & Total & Missing value \\
\hline Male & 80 & 71 & 151 & 167 \\
Female & 88 & 79 & 318 & $20^{\mathrm{a}}$ \\
Total & 168 & 150 & ${ }^{a}$ Twenty students did not complete the grade and gender questions.
\end{tabular}

\section{B. Materials}

The questionnaire was first drawn up in English and translated into Japanese by the author. The questionnaire was translated back into English by two Japanese undergraduates at an Australian university. This back-translation was then cross-checked and reconciled with the original questionnaire by the author. In addition to demographic information, the survey also sought to elicit participants" awareness about the notion of "Anglophone countries". Participants were asked in which country (or region) they think people primarily speak English. This item was included in order to see whether participants associate the notion of Anglophone countries with a setting in which English is the primary language and participants would use English mainly with native speakers of the language.

The questionnaire included two instruments: Instruments 1 and 2 (see the Appendix). Instrument 1 (Items 1-6) contained 5-point semantic-differential items to ascertain students' attitudes toward six different varieties of English: UK, US, India, Singapore, Japanese, and China varieties. The former two native varieties were the dominant role models for Japanese learners (Loveday, 1996; Morrow, 2004). The other four were selected from Asian regions in line with Kachru's three-circle categories (1985). The India and Singapore varieties were selected as institutionalized Outer Circle varieties in the World Englishes literature (e.g., Kachru, 1982). Japanese and China varieties were selected as performance varieties (e.g., Kachru, 1982) representing the Expanding Circle. The instrument contained six bi-polar adjectives to measure attitudes toward each variety of English.

Instrument 2 (Items 7a-8h) was designed to see in which frame - the native speaker or the lingua franca setting - the participants' attitudes to the goals of learning English display more magnitude. The instrument included eight items to measure the integrative and instrumental elements of attitudes to the goals of learning a second language as envisioned in the social psychological perspective of L2 motivation (Gardner, 1985). To reiterate, this is not to say that the study intended to probe the immense complexity of L2 motivation per se (Dörnyei \& Ushioda, 2009; 2011). Rather, the study focussed on these attitudinal elements with a view to a preliminary insight into the native speaker ideal among Japanese middle school EFL learners. Thus, the study sought to elicit participants' dispositions along this line. That is, in terms of two frames by repeating each question with the frame being either native speaker or lingua franca setting. This design was intended to measure participants' dispositions with respect to these two different frames.

While the items on the questionnaire were separate ones, collapsing them into one composite score was pursued in order to facilitate the comparison and reporting of the results. The study post hoc checked the appropriateness of collapsing them into one composite score for attitudinal and motivational dispositions, respectively. The appropriateness of this procedure was supported as in the subsequent measurement reporting. The items were thus found to indicate either positive or negative dispositions toward the varieties of English and English language learning in the two different frames. The composite scores were then used for attitudinal inferences in terms of native speaker orientations.

\section{Procedure}

The final version of the questionnaire was personally delivered to the school by the author. The questionnaire was administered during the teaching hours of the school. The teaching staff members who had agreed to take charge of the administration of the survey distributed the questionnaires among participants. Participation was consent-based, anonymous, and withdrawable at any point during the administration. The completed questionnaires were collected by the teaching staff and passed on to the author. The questionnaires were then computer-coded, and the data were analyzed on SPSS 17.0. In order to minimize the probability of committing a Type I error, the study set the alpha level at .01. The data were subjected to tests of normality and skewness. While the distributions for a large number of items were positively or negatively skewed, this did not rule out the use of t-tests for the inferential statistical analysis, as t-tests are considered a fairly robust procedure (Sheskin, 2007, p. 453). 


\section{RESUlts}

\section{A. Anglophone Countries}

Whilst some students named two or more countries as being Anglophone, the vast majority of them $(n=309)$ provided as their sole or first answer either the US $(n=269)$, the UK $(n=38)$, or Australia $(n=2)$ where English is the primary language. This result accords with Matsuda's (2003) finding (see Introduction), evincing that the participants of this study strongly associated the notion of Anglophone countries with a setting where English is used primarily for communication among its native speakers.

\section{B. Attitudes to the Varieties of English}

In order to facilitate a comparison of attitudinal differences with regards to the six language varieties in question, the study collapsed the six items to constitute a composite attitude scale. Prior to this operation, the study examined the appropriateness of collapsing the six separate items on Instrument 1 into one composite score for attitudinal disposition to the target language. This was done by interpreting an index of reliability. Internal consistency of the items for each variety of English was examined by using Cronbach's alpha. The alphas were very high, ranging from .918 to .960 (Table 2). This result supported the collapsing of the separate items into one composite score for attitudinal disposition to the target language. Hence, the items were aggregated to form a composite language attitude scale with negative and positive disposition towards the variety of English in question being the interpretative continuum for the scale. The scale as a whole was labeled Attitudinal Disposition (hence, AD). The attitudes measured for each variety of English were labeled ADUK (attitudinal disposition toward UK English), ADSP (Singapore English), ADUS (US English), ADJP (Japanese English), ADIN (India English), and ADCH (China English).

TABLE 2 ALPHA VALUES AND DESCRIPTIVE STATISTICS OF THE ATTITUDINAL DISPOSITIONS

\begin{tabular}{lllll}
\hline & $\alpha$ & $N$ & $M$ & $S D$ \\
\hline ADUS & .936 & 318 & 19.7 & 6.36 \\
ADJP & .952 & 318 & 16.9 & 6.39 \\
ADUK & .918 & 318 & 16.3 & 5.70 \\
ADSP & .938 & 318 & 14.1 & 5.05 \\
ADCH & .952 & 318 & 13.8 & 5.58 \\
ADIN & .960 & 318 & 13.3 & 5.54 \\
\hline Note. ADUK = Attitude to UK English; ADSP = Attitude to Singapore English; ADJP = Attitude to Japanese English; ADUK = Attitude to UK
\end{tabular}
English; ADIN = Attitude to India English; ADCH = Attitude to China English.

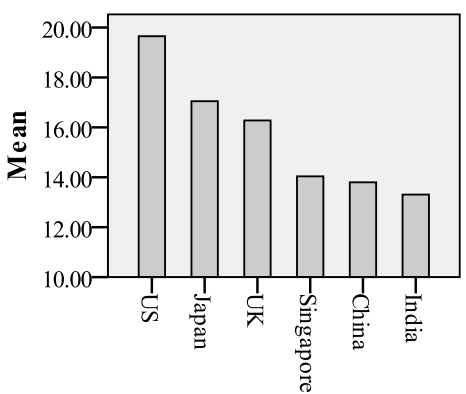

Figure 1Means for attitudinal dispositions

Table 2 shows the descriptive statistics of the attitudinal dispositions toward each variety of English. Paired-samples t-tests were conducted to see the possible differences between these dispositions (cf. Figure 1). The result showed that there was a significant difference between ADUS $(M=19.7, S D=6.36, N=318)$ and ADJP $(M=16.9, S D=6.39, N=$ $318), t(317)=6.53, p=.000$, and $\operatorname{ADUK}(M=16.3, S D=5.70, N=318)$ and $\operatorname{ADSP}(M=14.1, S D=5.05, N=318)$ $t(317)=9.48, p=.000$. It is notable that there was not a significant difference in scores for ADJP $(M=16.9, S D=6.39$, $N=318)$ and $\operatorname{ADUK}(M=16.3, S D=5.70, N=318), t(317)=-1.25, p=.213$.

\section{Attitudes to English Language Learning}

The study examined the appropriateness of collapsing the eight separate items on Instrument 2 into one composite score for motivational disposition in the two - native and lingua franca-frames. This was done by interpreting an index of reliability. Internal consistency of the items for each frame was examined by using Cronbach's alpha. The alphas were very high, .935 for MDNS and .941 for MDLF. This result supported the collapsing of the separate items into one composite score for motivational disposition in both frames. Hence, the items were aggregated to form a composite scale with negative or positive disposition towards English language learning being the interpretative continuum for the scale. The scale was labelled Motivational Disposition (hence, MD). The motivational dispositions in each frame were labelled MDNS (MD in the native speaker frame) and MDLF (MD in the lingua franca frame), respectively (Table 3). Following on from this, the scores for MDNS and MDLF were compared by conducting a paired-samples t-test. There was a significant difference in terms of scores for $\operatorname{MDNS}(M=26.9, S D=8.70, N=318)$ and $\operatorname{MDLF}(M=23.1, S D=$ 
$8.54, N=318), t(317)=10.0, p=.000$.

TABLE 3

ALPHA VALUES AND DESCRIPTIVE STATISTICS OF MOTIVATIONAL DISPOSITIONS

\begin{tabular}{lllll}
\hline & $\alpha$ & $N$ & $M$ & $S D$ \\
\hline MDNS & .935 & 318 & 26.9 & 8.70 \\
MDLF & .941 & 318 & 23.1 & 8.54 \\
\hline
\end{tabular}

Note. MDNS = motivational disposition in the native speaker frame; MDLF = motivational disposition in the lingua franca frame.

\section{The Age and Gender Variation}

Table 4 compares the means of AD for the two grade (in lieu of age) groups. An independent-samples t-test detected a significant difference in terms of ADUK between the two groups. In addition, there was no significant difference with regard to ADJP between them. It is notable that the effect size ${ }^{2}$ (i.e., Cohen's $d$ ) of this age difference for ADUK was more than double the value of these for ADUS and ADSP. In parallel, Table 5 compares the means of MD for the two grade groups. An independent-samples t-test detected a significant difference in terms of MDNS between the two groups with the effect size being more than triple the amount of that for MDLF.

TABLE 4

CONTRAST OF EIGHTH AND NINTH GRADERS' ATTITUDINAL DISPOSITIONS

\begin{tabular}{|c|c|c|c|c|c|c|c|c|c|c|}
\hline & \multicolumn{2}{|c|}{ Grade 8} & \multicolumn{2}{|c|}{ Grade 9} & \multirow[b]{2}{*}{$d f$} & \multirow[b]{2}{*}{$t$} & \multirow[b]{2}{*}{$p$} & \multicolumn{2}{|c|}{$99 \% \mathrm{CI}$} & \multirow[b]{2}{*}{ Cohen's $d$} \\
\hline & $M$ & $S D$ & $M$ & $S D$ & & & & $L L$ & $U L$ & \\
\hline ADUS & 19.0 & 6.20 & 20.4 & 6.47 & 316 & -2.08 & .038 & -3.32 & 0.36 & -0.22 \\
\hline ADJP & 17.1 & 6.07 & 16.5 & 6.73 & 316 & 0.83 & .410 & -1.27 & 2.45 & 0.09 \\
\hline ADUK & 15.1 & 5.47 & 17.7 & 5.66 & 316 & -4.14 & .000 & -4.21 & -0.97 & -0.47 \\
\hline ADSP & 13.6 & 5.22 & 14.6 & 4.82 & 316 & -1.74 & .082 & -2.45 & 0.48 & -0.20 \\
\hline $\mathrm{ADCH}$ & 13.7 & 5.60 & 13.9 & 5.60 & 316 & -0.27 & .791 & -1.79 & 1.46 & -0.04 \\
\hline ADIN & 12.9 & 5.43 & 13.8 & 5.64 & 316 & -1.34 & .181 & -2.82 & 0.60 & -0.16 \\
\hline
\end{tabular}

Note. $\mathrm{CI}=$ confidence interval; $\mathrm{LL}=$ lower limit; UL = upper limit. ADUK = Attitude to UK English; ADSP = Attitude to Singapore English; ADJP = Attitude to Japanese English; ADUK = Attitude to UK English; ADIN = Attitude to India English; ADCH = Attitude to China English.

TABLE 5

CONTRAST OF EIGHTH AND NINTH GRADERS' MOTIVATIONAL DISPOSITIONS

\begin{tabular}{|c|c|c|c|c|c|c|c|c|c|c|}
\hline & \multicolumn{2}{|l|}{ Grade 8} & \multicolumn{2}{|c|}{ Grade 9} & \multirow[b]{2}{*}{$d f$} & \multirow[b]{2}{*}{$t$} & \multirow[b]{2}{*}{$p$} & \multicolumn{2}{|c|}{$99 \% \mathrm{CI}$} & \multirow[t]{2}{*}{ Cohen's $d$} \\
\hline & $M$ & $S D$ & $M$ & $S D$ & & & & $L L$ & $U L$ & \\
\hline MDNS & 25.7 & 8.58 & 28.3 & 8.66 & 316 & -2.69 & .008 & -5.11 & -0.09 & -0.30 \\
\hline MDLF & 22.7 & 8.49 & 23.4 & 8.63 & 316 & -0.74 & .461 & -3.20 & 1.78 & -0.08 \\
\hline
\end{tabular}

Note. $\mathrm{CI}=$ confidence interval; $\mathrm{LL}=$ lower limit $\mathrm{UL}=$ upper limit; MDNS = motivational disposition in the native speaker frame; MDLF = motivational disposition in the lingua franca frame.

Table 6 compares the means of AD for the two gender groups. There was a significant difference in terms of ADUK and ADUS between the two groups. That is, the means of ADUK and ADUS for females were significantly larger than those of the male students. Although the score of ADSP for female students was also significantly greater than that of the male, an interpretation of the effect sizes suggests that the magnitude of this gender difference is larger for ADUK and ADUS than for ADSP. Meanwhile, Table 7 compares the means of MD for the two gender groups. An independent-samples t-test showed that there is a significant difference in terms of MDNS between male and female students. The mean of MDNS for females was significantly greater than that of the male students.

TABLE 6

CONTRAST OF MALE AND FEMALE ATTITUDINAL DISPOSITIONS

\begin{tabular}{|c|c|c|c|c|c|c|c|c|c|c|}
\hline & \multicolumn{2}{|l|}{ Male } & \multicolumn{2}{|c|}{ Female } & \multirow[b]{2}{*}{$d f$} & \multirow[b]{2}{*}{$t$} & \multirow[b]{2}{*}{$p$} & \multicolumn{2}{|c|}{$99 \% \mathrm{CI}$} & \multirow[b]{2}{*}{ Cohen's $d$} \\
\hline & $M$ & $S D$ & $M$ & $S D$ & & & & $L L$ & $U L$ & \\
\hline ADUS & 18.4 & 6.72 & 20.8 & 5.81 & 316 & -3.40 & .001 & -4.21 & -0.57 & -0.38 \\
\hline ADJP & 16.7 & 6.83 & 17.0 & 5.97 & 316 & -0.31 & .758 & -2.08 & 1.64 & -0.05 \\
\hline ADUK & 15.1 & 6.06 & 17.4 & 5.21 & 295.1 & -3.77 & .000 & -4.02 & -0.74 & -0.41 \\
\hline ADSP & 13.3 & 5.47 & 14.8 & 4.54 & 292.7 & -2.61 & .009 & -2.95 & -0.03 & -0.30 \\
\hline $\mathrm{ADCH}$ & 13.3 & 5.82 & 14.4 & 5.33 & 316 & -1.76 & .079 & -2.72 & 0.52 & -0.20 \\
\hline ADIN & 13.2 & 6.17 & 13.4 & 4.92 & 286.5 & -0.39 & 697 & -1.88 & 1.39 & -0.04 \\
\hline
\end{tabular}

Note. $\mathrm{CI}=$ confidence interval; $\mathrm{LL}=$ lower limit; UL = upper limit. ADUK = Attitude to UK English; ADSP = Attitude to Singapore English; ADJP = Attitude to Japanese English; ADUK = Attitude to UK English; ADIN = Attitude to India English; ADCH = Attitude to China English.

TABLE 7

CONTRAST OF MALE AND FEMALE MOTIVATIONAL DISPOSITIONS

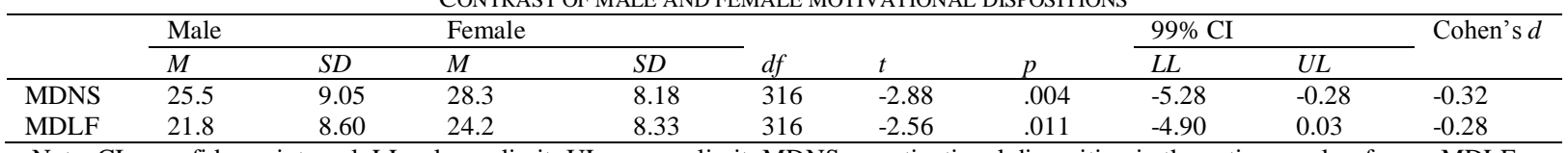

Note. $\mathrm{CI}=$ confidence interval; $\mathrm{LL}=$ lower limit $\mathrm{UL}=$ upper limit; MDNS = motivational disposition in the native speaker frame; $\mathrm{MDLF}=$ motivational disposition in the lingua franca frame. 


\section{E. Limitations}

A notable limitation of the study is that the measurement items asked the participants direct questions about language evaluation and preference drawing upon the overt elicitation of attitudes. This method might have elicited the attitudes that they are normally prepared to tell people about, coupled with the dominant stereotypical disposition of the community that the students inhabit towards the speakers of these language varieties in question (see Edwards, 1982). An indirect measure (i.e., matched- or verbal-guise technique which uses recorded speech samples of the varieties of English as vocal cues $^{3}$ ) might have produced different findings such as their subconsciously held private views about language variation (cf. Kristiansen, 2009). This issue considered, the extent to which the scales have ascertained what the study claims to have measured draws attention to their internal validity. Meanwhile, although the demonstrated age-stratified variations in language attitudes may be hypothesized as representing an attitudinal change in progress, this can only be confirmed by real-time evidence (Eckert, 1997), which involves sampling the population for a prolonged period of time. This demands further empirical verification in this respect. Future studies should incorporate a longitudinal component in order to ascertain this element.

Given that the education system of Japan is highly centralized and the Course of Study policy documents penetrate both the public and private sectors of education (e.g., DeCoker, 2002), a certain degree of uniformity and standardization in pedagogy can be anticipated. To this extent, the results of this study may be generalizable to other middle school students in similar social, educational, and areal situations in Japan. The author extrapolates from the data, coupled with past studies of language attitudes and language ideology in Japan (e.g., Honna, 1995; Matsuda, 2003; Seargeant, 2009) as well as folk anecdotes concomitant with the author's own personal experiences, that a certain level of native speaker orientation may be anticipated for this segment of population also (i.e., middle school students). However, the author would note that an overgeneralization must be refrained. To raise a couple of possibilities among others, students' orientation may be subject to the particular pedagogical approach taken (or not taken) at each school with regard to the native speaker orientation. This study did not pursue such empirical information. These limits recognized, the findings are discussed in what follows.

\section{DISCUSSION}

As the attitudinal profile of the participants demonstrates, these middle school students have different attitudes toward different varieties of English. Specifically, they evaluate US English $(M=19.7$; cf. the mid point being 18 out of 30) most positively among the six varieties. While they evaluate the other varieties of English negatively, they evaluate UK $(M=16.3)$ and Japanese $(M=16.9)$ English similarly. In contrast, as t-tests indicate, they hold clearly negative attitudes to the other nonnative varieties of English such as China and India English. Thus, the students in this study have discriminative attitudes toward different varieties of English as early as at middle school. This finding is congruous with the previous research in this respect that reported Japanese discriminative attitudes towards native and nonnative varieties in different segments of the population (e.g., Honna, 1995; Honna \& Takeshita, 2000; Matsuda, 2002; 2003; Saito \& Hatoss, 2011). The analysis has also revealed that they show a more positive disposition toward English language learning in the native speaker than in the lingua franca frame. This result suggests that Japanese middle school students opt for learning English for its utility in the native speaker setting, rather than for its transnational instrumentality in a lingua franca setting.

The examination of the age-stratified variation in their dispositions indicates that the students' attitudes to UK English as a native variety significantly change in the positive direction during the one-year time span in transition from Grade 8 to 9. In parallel, it is notable that Japanese English is evaluated positively in relative terms among the six varieties of English, as there was no significant difference between attitudes to UK and those to Japanese English. This is in stark contrast to the attitudes expressed by high school students in Japan. Saito and Hatoss (2011) examined language attitudes among high school students in Japan (i.e., Grades 11 and 12) with the same survey format of this paper. Their study revealed that the students had the most negative attitudes to Japanese English among the same six varieties of English, while showing the most positive attitudes to US and UK English. As opposed to the middle school students in this study, these high school students therefore clearly differentiated between these native English varieties and the Japanese variety. These age variations can be considered to be a preliminary indication of the developmental trajectory of a native speaker ideal among Japanese secondary school students. Meanwhile, the gender variation suggests that the females may be leading in the development of a native speaker orientation, with regard to the motivational orientations in particular.

\section{CONCLUSION}

This study provides a preliminary insight into the native speaker orientation among middle school EFL students in Japan. The students in this study certainly distinguish native and non-native varieties of English as well as native and lingua franca settings. They value native English and envision use of English in the native speaker setting. Thus, their commitment to a native speaker ideal implies that they may envision the target speech community of English, contrary to the current scholarly theorizing of English as the language of a global transnational community. This suggests that the status of the "target speech community" as viewed by the language learner merits further empirical investigation. 
Finally, this study raised but not resolved the issue of where the students' commitment to a native speaker ideal comes from. There are a range of sources through which this ideal may be conceived such as folk anecdotes, media discourses, overseas travelling, and so forth. In unison with the point made by Matsuda (2002) earlier, the author speculates that the major source of this native speaker ideal might be the current teaching material and pedagogical practices as aforementioned, although this causal link cannot be demonstrated without empirical evidence. Although without evidence in this respect, the paper does demonstrate that the native speaker orientation calls for an educational intervention at middle school when the vast majority of Japanese embark on EFL. The author would argue that the intervention ought not to be deferred to a later stage, say, at high school when students' discriminative attitudes to native and nonnative varieties of English become articulate (Saito \& Hatoss, 2011). From this pedagogical perspective, the insight from the English as a lingua franca approach (e.g., Jenkins, 2009; Kirkpatrick, 2007; Mauranen, 2006; Seidlhofer, 2003) certainly contributes to a construction of pedagogy which encourages an adoption of English as a means of international communication among secondary students in Japan.

On the other hand, one would be better off not supposing the teaching that students receive only influences their perception and attitudes. In his elaborate account of the idea of the English language as manifest in Japanese society, Seargeant (2009) notes that it might be true that alterations to syllabus and teacher training would bring about profound effects with a view to raising awareness about the use and varieties of English as a lingua franca. But this would be the case if the students' attitudes are considered merely to be a direct reflection of the teaching that they receive (Seargeant, 2009 , p. 94). Seargeant thus points to the need to view the pedagogical practices and student dispositions pertaining to the English language in the broader social sphere within which language learning takes place:

$[D]$ ifferent cultures construct their own profiles and purposes for the English language, and ... in certain contexts these profiles can in fact obstruct the easy adoption of the language as a form of international communication while still allowing it to fulfill other significant functions within society. (Seargeant, 2009, p. 89)

As students proceed with learning at school and grow older, they may become inducted and socialized into particular (pedagogical and) social practices relating to the English language as in Japanese society. This implies further research that features the trajectory of language attitudes of secondary students in Japan.

\section{NOTES}

1. While foreign languages are taught as a required subject at middle and high school in Japan (MEXT, 2003), most secondary schools teach English because of the foreign language requirement for degrees at many tertiary institutions and the consequent emphasis on English in high school and university entrance examinations (Gottlieb, 2005, p. 31). Compulsory foreign language activities are scheduled to be implemented at primary level (grades 5 and 6) in 2011 (MEXT, 2008).

2. Effect size enables a comparison of the results in different studies (see Dörnyei, 2007, p. 212 for more details).

3. That being said, matched- and verbal-guise studies also cannot avoid criticism in terms of internal and external validity. See Garrett (2010) and Knops and Hagen (1989) for a summary of such criticisms.

\section{ACKNOWLEDGEMENTS}

I thank Dr Warren Midgley and Mr Syaril Izwann Jabar for their helpful comments on an earlier version of this paper. I am grateful to Dr Midgley for proofreading an earlier version of this manuscript for grammatical and typological errors. All remaining errors are mine and mine alone.

\section{APPENDIX: THE QUESTIONNAIRE}

\section{Instrument 1:}

1. What impression do you have of UK English? Please circle the number for each item that best positions your answer.

\begin{tabular}{|c|c|c|c|c|c|c|}
\hline Uncool & 1 & 2 & 3 & 4 & 5 & Cool \\
\hline Unimportant & 1 & 2 & 3 & 4 & 5 & Important \\
\hline Lacking prestige & 1 & 2 & 3 & 4 & 5 & Prestigious \\
\hline Powerless & 1 & 2 & 3 & 4 & 5 & Powerful \\
\hline Unpopular & 1 & 2 & 3 & 4 & 5 & Popular \\
\hline Unfashionable & 1 & 2 & 3 & 4 & 5 & Fashionable \\
\hline
\end{tabular}

\section{Instrument 2:}

7. Do you agree or disagree with these statements? Please tick in one box for each item that best positions your answer. 


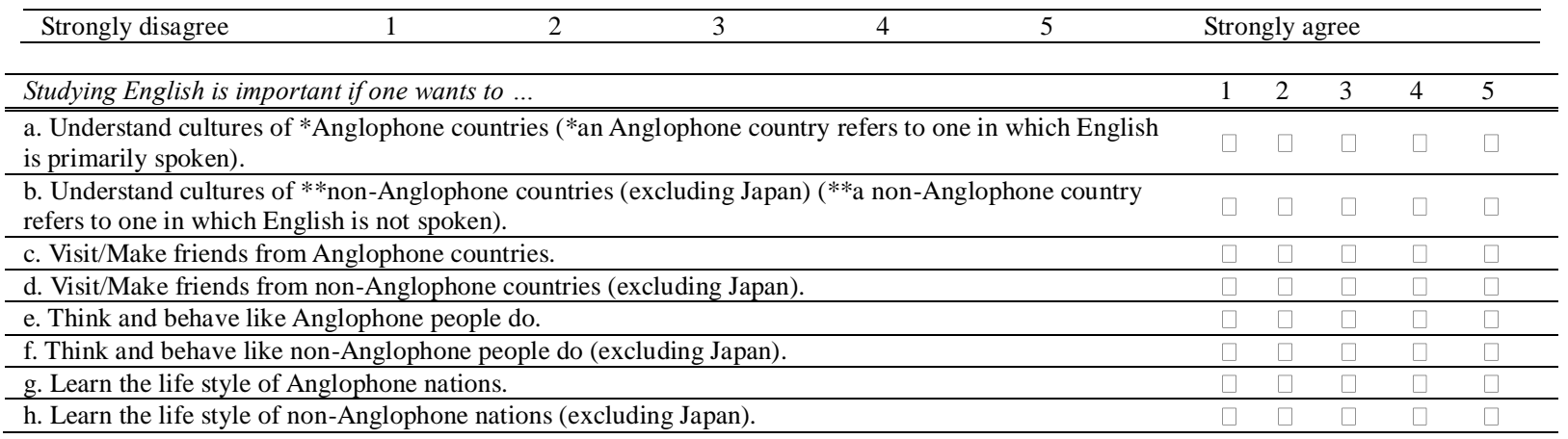

8. Do you agree or disagree with these statements? Please tick in one box for each item that best positions your answer.

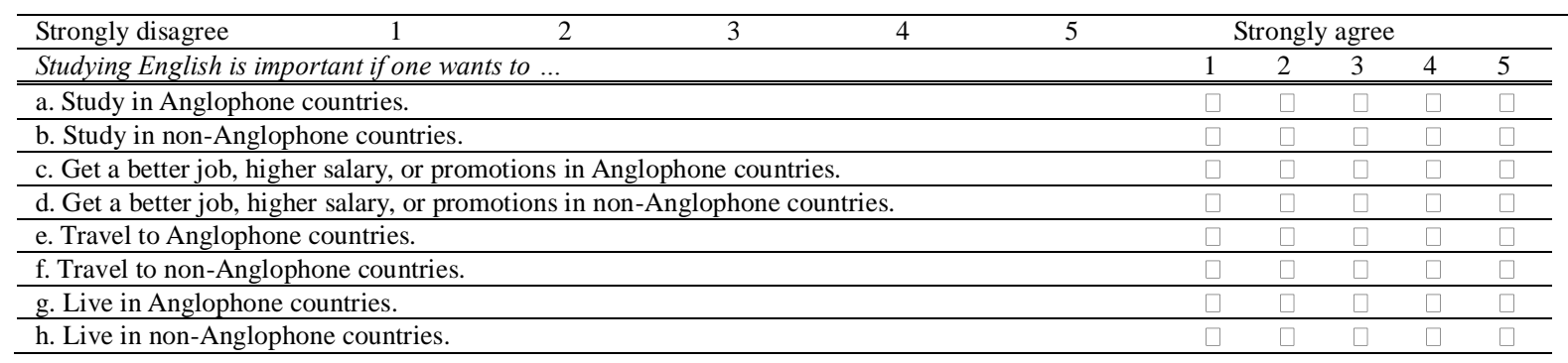

\section{REFERENCES}

[1] Ajzen, I. (1996). The directive influence of attitudes on behavior. In P. M. Gollwitzer \& J. A. Bargh (Eds.), The psychology of action: Linking cognition and motivation to behavior (pp. 385-403). Guilford: New York, NY.

[2] Ajzen, I., \& Fishbein, M. (1980). Understanding attitudes and predicting social behaviour. Englewood Cliffs, NJ: Prentice Hall.

[3] Aronson, E., Wilson, T. D., \& Akert, R. M. (2005). Social psychology (5th ed.). Upper Saddle River, NJ: Prentice Hall.

[4] Baker, C. (1992). Attitudes and language. Clevedon, UK: Multilingual Matters.

[5] Brutt-Griffler, J. (2002). World English: A study of its development. Clevedon, UK: Multilingual Matters.

[6] Chiba, R., Matsuura, H., \& Yamamoto, A. (1995). Japanese attitudes toward English accents. World Englishes, 14(1), 77-86.

[7] Crystal, D. (1997). English as a global language. New York, NY: Cambridge University Press.

[8] Davies, A. (2003). The native speaker: Myth and reality (2nd ed.). Clevedon, UK: Multilingual Matters.

[9] DeCoker, G. (Ed.). (2002). National standards and school reform in Japan and the United States. Williston, VT: Teachers College Press.

[10] Doerr, N. M. (Ed.). (2009). The native speaker concept: Ethnographic investigations of native speaker effects. Berlin, Germany: Mouton De Gruyter.

[11] Dörnyei, Z. (2005). The psychology of the language learner: Individual differences in second language acquisition. Mahwah, NJ: Lawrence Erlbaum Associates.

[12] Dörnyei, Z. (2007). Research methods in applied linguistics: Quantitative, qualitative and mixed methodologies. Oxford, UK: Oxford University Press.

[13] Dörnyei, Z., Csizér, K., \& Németh, N. (2006). Motivation, language attitudes and globalisation: A Hungarian perspective. Clevedon, UK: Multilingual Matters.

[14] Dörnyei, Z., \& Ushioda, E. (Eds.). (2009). Motivation, language identity and the L2 self. Bristol, UK: Multilingual Matters.

[15] Dörnyei, Z., \& Ushioda, E. (2011). Teaching and researching motivation (2nd ed.). Harlow, UK: Pearson Education.

[16] Eckert, P. (1997). Age as a sociolinguistic variable. In F. Coulmas (Ed.), The Handbook of Sociolinguistics (pp. 151-167). Oxford, UK: Blackwell.

[17] Edwards, J. R. (1979). Language and disadvantage. London, UK: Edward Arnold.

[18] Edwards, J. R. (1982). Language attitudes and their implications among English speakers. In E. B. Ryan \& H. Giles (Eds.), Attitudes towards language variation: Social and applied contexts (pp. 20-33). London, UK: Edward Arnold.

[19] Fraser, S. (2006). Perceptions of varieties of spoken English: Implications for EIL. In R. Kiely, P. Rea-Dickins, H. Woodfield \& G. Clibbon (Eds.), Language, culture and identity in applied linguistics (Vol. 21, pp. 79-97). London, UK: Equinox.

[20] Gardner, R. C. (1985). Social psychology and second language learning: The role of attitudes and motivation. London, UK: Edward Arnold.

[21] Gardner, R. C., \& Lambert, W. E. (1972). Attitudes and motivation in second-language learning. Rowley, MA: Newbury House.

[22] Garrett, P. (2010). Attitudes to language. Cambridge, UK: Cambridge University Press.

[23] Garrett, P., Coupland, N., \& Williams, A. (2003). Investigating language attitudes: Social meanings of dialect, ethnicity and performance. Cardiff, UK: University of Wales Press.

[24] Goddard, J. (2001). Which varieties of English do you teach at Jr./Sr. high school? The Language Teacher, 25(8), 21-24.

[25] Gottlieb, N. (2005). Language and society in Japan. Cambridge, UK: Cambridge University Press. 
[26] Graddol, D. (2006). English next: Why Global English may mean the end of 'English as a Foreign Language'. In B. Council (Ed.). London, UK: British Council.

[27] Greenwald, A. G., \& Banaji, M. R. (1995). Implicit social cognition: Attitudes, self-esteem, and stereotypes. Psychological Review, 102(1), 4-27.

[28] Honna, N. (1995). English in Japanese society: language within language. Journal of Multilingual and Multicultural Development, 16(1\&2), 45-62.

[29] Honna, N., \& Takeshita, Y. (2000). English language teaching for international understanding in Japan. EA Journal, 18(1), 60-78.

[30] Jenkins, J. (2007). English as a lingua franca: Attitudes and identity. Oxford, UK: Oxford University Press.

[31] Jenkins, J. (2009). English as a lingua franca: Interpretations and attitudes. World Englishes, 28(2), 200-207.

[32] Joe, M. (2010, April 15). Why do English teachers have to be native speakers? English-language schools in Japan are changing stereotypes by proving that good teaching is not about nationality. The Japan Times. Retrieved November 11, 2011, from http://search.japantimes.co.jp/cgi-bin/fs20100415a3.html

[33] Kachru, B. (Ed.). (1982). The other tongue: English across cultures. Oxford, UK: Pergamon Press.

[34] Kachru, B. (1985). Standards, codification, and sociolinguistic realism: The English language in the outer circle. In R. Quirk \& H. Widdowson (Eds.), English in the world: Teaching and learning the language and literatures (pp. 11-30). Cambridge, UK: Cambridge University Press.

[35] Kachru, B., Kachru, Y., \& Nelson, C. L. (Eds.). (2006). The handbook of world Englishes. Malden, MA: Blackwell.

[36] Kirkpatrick, A. (2007). World Englishes: Implications for international communication and English language teaching. Cambridge, UK: Cambridge University Press.

[37] Knops, U., \& Hagen, A. M. (1989). Paradigms in sociophonetic research. In M. E. H. Schouten \& P. T. van Reenen (Eds.), New methods in dialectology (pp. 87-105). Dordrecht, The Netherlands: Foris.

[38] Kravchenko, A. V. (2010). Native speakers, mother tongues and other objects of wonder. Language Sciences, 32(6), 677-685.

[39] Kristiansen, T. (2009). The macro-level social meanings of late-modern Danish accents. Acta Linguistica Hafniensia: International Journal of Linguistics, 41(1), 167 - 192.

[40] Loveday, L. J. (1996). Language contact in Japan: A socio-linguistic history. New York, NY: Oxford University Press.

[41] Matsuda, A. (2002). Representation of users and uses of English in beginning Japanese EFL textbooks. JALT Journal, 24(2), $182-200$.

[42] Matsuda, A. (2003). The ownership of English in Japanese secondary schools. World Englishes, 22(4), 483-496.

[43] Matsuura, H., Chiba, R., \& Yamamoto, A. (1994). Japanese college students' attitudes towards non-native varieties of English. In D. Graddol \& J. Swann (Eds.), Evaluating language: Papers from the Annual Meeting of the British Association for Applied Linguistics held at the University of Essex, September 1992 (pp. 52-61). Clevedon, UK: British Association for Applied Linguistics in association with Multilingual Matters.

[44] Mauranen, A. (2006). Signaling and preventing misunderstanding in English as lingua franca communication. International Journal of the Sociology of Language, 177, 123-150.

[45] Ministry of Education, Culture, Sport, Science, and Technology (MEXT). (2003). Regarding the establishment of an action plan to cultivate "Japanese with English abilities". Retrieved November 11, 2011, from http://www.mext.go.jp/b_menu/shingi/chousa/shotou/020/sesaku/020702.htm

[46] Ministry of Education, Culture, Sport, Science, and Technology (MEXT). (2008). Shogakkô gakushû shidôyôryô kaisetsu: gaikokugo katsudô hen [Handbook for the elementary school course of study: foreign language activities]. Retrieved November 11, 2011, from http://www.mext.go.jp/a_menu/shotou/new-cs/youryou/syokaisetsu/012.zip

[47] Morrow, P. R. (2004). English in Japan: The World Englishes perspective. JALT Journal, 26(1), 79-100.

[48] Niedzielski, N. A., \& Preston, D. R. (2000). Folk linguistics. Berlin, Germany; New York, NY: Mouton de Gruyter.

[49] Pennycook, A. (2007). Global Englishes and transcultural flows. New York, NY: Routledge.

[50] Riley, P. (1997). The guru and the conjurer: Aspects of counselling for self-access. In P. Benson \& P. Voller (Eds.), Autonomy and independence in language learning (pp. 114-131). New York, NY: Longman.

[51] Ryan, E. B., \& Giles, H. (Eds.). (1982). Attitudes towards language variation: Social and applied contexts. London, UK: Edward Arnold.

[52] Saito, Y. (2006). Consequences of high-stakes testing on the family and schools in Japan. KEDI Journal of Educational Policy, $3(1), 101-112$.

[53] Saito, A., \& Hatoss, A. (2011) Does the ownership rest with us? Global English and the native speaker ideal among Japanese high school EFL students. International Journal of Pedagogies and Learning, 6(2), 108-125.

[54] Sakai, S. (2005). Introduction. World Englishes, 24(3), 321-322.

[55] Seargeant, P. (2005). 'More English than England itself': The simulation of authenticity in foreign language practice in Japan. International Journal of Applied Linguistics, 15(3), 326-345.

[56] Seargeant, P. (2009). The idea of English in Japan: Ideology and the evolution of a global language. Bristol, UK: Multilingual Matters.

[57] Seidlhofer, B. (2001). Closing a conceptual gap: The case for a description of English as a lingua franca. International Journal of Applied Linguistics, 11(2), 133-158.

[58] Seidlhofer, B. (2003). A concept of international English and related issues: From 'real English' to 'realistic English'? Strasbourg, France: Council of Europe Retrieved November 11, 2011, from www.coe.int/t/dg4/linguistic/source/seidlhoferen.pdf

[59] Sheskin, D. (2007). Handbook of parametric and nonparametric statistical procedures (4th ed.). Boca Raton, FL: Chapman \& Hall/CRC.

[60] Starks, D., \& Paltridge, B. (1996). A note on sociolinguistic methods to study non-native attitudes towards English. World Englishes, 15(2), 217-224. 
Akihiro Saito is Assistant Professor in the Centre for Liberal Arts and Sciences at the Hachinohe Institute of Technology - Aomori, Japan. The topic of his dissertation is the discursive construction of language attitudes of Japanese sojourner youth studying English at an Australian university. His interests include various themes in the fields of applied linguistics and sociolinguistics such as, attitudes, motivation, identity, and their implications for language pedagogy. 